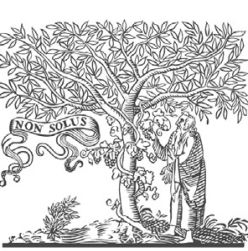

\title{
Impact of hepatitis B and delta virus co-infection on liver disease in Mauritania: A cross sectional study
}

\author{
Françoise Lunel-Fabiani ${ }^{\text {a,b,*,h }}$, Wael Mansour ${ }^{\text {a,b,d,e,h }}$, \\ Abdellahi Ould Amar ${ }^{c}$, Mohamed Aye ${ }^{c}$, Frédéric Le Gal d,e, \\ F- Zahra Fall Malick ${ }^{f}$, Lô Baïdy ${ }^{f}$, Ségolène Brichler ${ }^{d, e}$, \\ Pascal Veillon ${ }^{a, b}$, Alexandra Ducancelle ${ }^{a, b}$, \\ Emmanuel Gordien ${ }^{\mathrm{d}, \mathrm{e}, \mathrm{h}}$, Michel Rosenheim ${ }^{\mathrm{g}, \mathrm{h}}$
}

a Laboratoire de virologie, $\mathrm{CHU}$ Angers, France

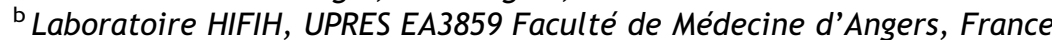

' Hepato-gastroenterology Department, National Hospital, Nouakchott, Mauritania

${ }^{\mathrm{d}}$ Service de Bactériologie, Virologie - Hygiène, Assistance Publique -Hôpitaux de Paris, Hôpitaux universitaires de Paris Seine Saint-Denis, Site Avicenne, Bobigny, France

e Laboratoire associé au Centre National de Référence des Hépatites B, C et Delta, Université Paris Nord, Sorbonne Paris Cité, France

${ }^{\mathrm{f}}$ National Public Health Institute, Nouakchott, Mauritania

' Université Pierre et Marie Curie, Paris, France et service de Santé Publique, Groupe Hospitalier Pitié-

Salpêtrière, Paris, France

Accepted 5 June 2013

Available online 22 June 2013

\section{KEYWORDS}

$\mathrm{HBV}$;

HDV;

Mauritania;

FibroMeter;

APRI;

Liver fibrosis;

Cirrhosis

\begin{abstract}
Summary Objectives: Mauritania is a highly endemic region for hepatitis B (HBV) and delta (HDV) viruses. No data are available on HDV's impact on the severity of liver disease in consecutive HBV-infected patients in Africa. This study evaluated the degree of liver fibrosis in a cohort of chronic HBV carriers.

Methods: Three-hundred consecutive HBV-infected Mauritanian patients were checked for HDV infection via the detection of anti-HDV antibodies (Ab) and viral RNA. HBV- vs. HBV/ HDV-infected patients were compared by physical examination, biological analyses, and the APRI (aspartate aminotransferase to platelet ratio index) and FibroMeter tests for determination of liver fibrosis.
\end{abstract}

\footnotetext{
* Corresponding author. Laboratoire de virologie, Département de biologie des agents infectieux et pharmaco-toxicologie, Institut de Biologie en Santé CHU d'Angers, 4, rue Larrey, 49933 Angers Cedex 9, France. Tel.: +332413547 09; fax: +33241354164.

E-mail address: FrLunel-Fabiani@chu-angers.fr (F. Lunel-Fabiani).

h Authors contributing equally to this work.
} 
Results: More than $30 \%$ of the patients had anti-HDVAb. Among these, $62.2 \%$ were HDV-RNA positive. Co-infected patients were older (>8-years) than HBV-mono-infected patients. They had more liver tests abnormalities and clinical or ultrasound signs of liver fibrosis. APRI and FibroMeter scores were also significantly increased in these patients. In multivariate analysis, beyond HDVAb, male gender and HBV-VL $>3.7 \mathrm{log} \mathrm{IU} / \mathrm{mL}$ were the only markers linked to significant liver fibrosis.

Conclusions: In Mauritania, HDV co-infection worsens liver disease, both clinically and biologically, as confirmed by the APRI and FibroMeter tests. These tests may be useful for the management of delta hepatitis, which is a major health problem in Mauritania.

(c) 2013 The British Infection Association. Published by Elsevier Ltd. All rights reserved.

\section{Introduction}

Hepatitis B virus (HBV) infection is a worldwide public health care problem. Two billion people have been infected with HBV and over 350 million of them are chronic carriers. Hepatitis delta virus (HDV) is a defective HBV-satellite RNA virus that requires $\mathrm{HBV}$ envelope proteins for its assembly and transmission. The global prevalence of HDV infection is poorly known due to a lack of studies in several parts of the world. It is estimated that approximately $5-20 \%$ of $\mathrm{HBsAg}$ carriers are also co-infected with HDV, i.e., 15-20 million HDV-infected individuals worldwide. Although a decline of HDV prevalence has been observed in European countries over the past decade, ${ }^{1,2}$ the infection remains highly endemic in sub-Saharan Africa. ${ }^{3-6}$ Very recently, we confirmed these data in Mauritania, where HBsAg prevalence varies from 10 to $20 \%$ in consulting patients, pregnant women or in blood donors. As much as $20 \%$ of these subjects are also infected with HDV., ${ }^{7,8}$

Many studies have demonstrated that HDV co- or superinfection may result in severe, acute or chronic liver diseases that progress more rapidly to cirrhosis. ${ }^{9-11}$

To avoid/limit liver biopsies while still providing an accurate evaluation of liver fibrosis in chronic liver diseases, several non-invasive tests have been proposed. For example, the APRI (aspartate aminotransferase to platelet ratio index) test, calculated as the ratio [(AST/upper limit of normal value: $45 \mathrm{IU} / \mathrm{L}) /$ platelet counts $\left.\left(10^{9} / \mathrm{L}\right)\right] \times 100,{ }^{12}$ is meant to evaluate the degree of fibrosis or cirrhosis; it has been validated for and is used in chronic hepatitis B. ${ }^{12,13}$ FibroMeter (FM) is another non-invasive diagnostic test of liver fibrosis. It is based on a mathematical algorithm that includes several biomarkers, ${ }^{14}$ these latter varying according to the cause of liver disease. In chronic viral hepatitis B or C, 7 variables are used: aspartate aminotransferase (AST), prothrombin time, platelets count, urea, $\gamma \mathrm{GT}, \alpha 2$ macroglobulin and hyaluronic acid. FM has been validated in many studies, both for hepatitis $C$ and hepatitis B. ${ }^{13,15}$

Conversely, validation studies for HDV have not been extensively performed. In a preliminary study, we showed that FM and liver stiffness measurement (LSM) were wellcorrelated and could accurately predict hepatic fibrosis stages in 41 patients with chronic hepatitis B or B/delta. Indeed, fibrosis scores determined by APRI, LSM or FM were significantly higher among patients who had HDV antibodies (anti-HDVAb) $(p<0.01){ }^{16}$

In the present study, we aimed to evaluate the impact of HDV on the severity of liver disease in 300 consecutive chronic carriers of hepatitis $B$ receiving care at the hepato- gastroenterology unit of the Nouakchott National Hospital of Mauritania (CHN) and lacking previous testing for HDV infection. We compared HBV- vs. HBV/HDV-infected patients via physical examination, laboratory tests and the 2 non-invasive liver fibrosis tests described above, APRI ${ }^{12}$ and FibroMeter ${ }^{14,17}$ (www.biolivescale.com) (FibroMeter, BioLiveScale, Angers, France). We also studied virological parameters such as anti-HDV antibodies (Ab), HBV-DNA and HDV-RNA viral load (VL), and genotypes.

\section{Patients and methods}

\section{Study population}

Three-hundred consecutive HBV-infected patients receiving care at the $\mathrm{CHN}$ were examined between February and October 2009. HBV infection was defined as the presence of hepatitis B surface antigen (HBsAg) in serum for at least 6 months. Exclusion criteria were: presence of anti hepatitis C (HCV) antibodies; HIV infection; evidence of metabolic or autoimmune liver disease; alcohol consumption $>40 \mathrm{~g} /$ day.

All the subjects were interviewed for demographical data and risk factors for HDV transmission including age, gender, ethnic group, nosocomial risks, history of transfusion or hospitalization, and injections with nondisposable syringes. The Ethics Committee of the Mauritanian Public Health Ministry approved this study $\left(\mathrm{N}^{\circ}\right.$ : 00000865) and all subjects gave their written informed consent before sample collection.

\section{Physical examination}

All patients were clinically examined and signs of liver insufficiency or portal hypertension, i.e., presence of jaundice, ascites, leg edema or liver or spleen enlargement were recorded. Ultrasound and upper endoscopy results were also recorded.

\section{Assessment of liver fibrosis}

The calculations for the APRI and FM scores to determine liver fibrosis were performed in the Angers laboratory. Concerning the laboratory analyses needed for score calculation, alanine aminotransferase (ALT), AST, prothrombin time, urea, $\gamma \mathrm{GT}$ and platelet counts were performed at the $\mathrm{CHN}$. The remaining analyses, $\alpha 2$ macroglobulin (BNII, Dade Behring, Marburg, Germany) and hyaluronic acid (Corgenix Inc. EIA, Biogenic SA, Maurin, France), were performed in Angers. 
We arbitrarily defined severe liver fibrosis (SLF) as a FM score $>0.9$. Significant fibrosis (SF) was defined as an APRI score $>1.5$, and the absence of SF as an APRI score $\leq 0.5$. Cirrhosis was defined as an APRI score $>2.0$ and the absence of cirrhosis as an APRI score $\leq 1.0$, as previously described. ${ }^{12}$

\section{Serological analyses}

Blood samples $(5-10 \mathrm{ml})$ were collected from all patients and sera were tested for $\mathrm{HBsAg}$ in the medical biology laboratory of the CHN using rapid tests (VIKIA-bioMerieux, Marcy l'étoile, France). Biochemical and hematological parameters were assessed by standard laboratory methods.

The sera were then sent to the virology laboratory of Angers University Hospital, France, and stored at $-80^{\circ} \mathrm{C}$ until use.

All samples were retested for HBsAg in Angers (Axsym, ABBOTT, Rungis, France). Confirmed positive samples $(n=298)$ were further tested for $\mathrm{HBe}$ antigen (HBeAg), anti-HBeAb, (DiaSorin, Antony, France) and anti-HDVAb (Total and IgM Abs) (DiaSorin, Antony, France).

\section{Molecular analysis}

Molecular tests, including HBV-DNA VL, HDV-RNA detection and/or VL quantification and genotyping, were performed in France, in the virology laboratories of Angers or Bobigny (Avicenne).

Nucleic acid extraction was performed using the NuclisENS Easy Mag platform (bioMerieux, Marcy l'étoile, France) according to the manufacturer's instructions, from $300 \mu \mathrm{L}$ of plasma or serum.

HBV-DNA was measured by a quantitative assay on the NucliSENS EasyQ platform (BioMerieux, Marcy l'étoile, France).

Quantification of HDV-RNA was determined by an inhouse, consensus, quantitative real-time PCR technique. ${ }^{18}$

$\mathrm{HDV}$ and $\mathrm{HBV}$ genotypes were determined by amplification of the $R O$ and the preS1 region (nt 2817-80) respectively, followed by sequencing and phylogenetic analyses. ${ }^{19,20}$

\section{Statistical analyses}

Student's test or Wilcoxon test when appropriate, were used for comparisons of continuous variables, and Pearson's chi-square or Fisher's exact test for categorical variables.

Variables linked to SLF, SF or cirrhosis, as defined above, with a $p$-value of 0.10 or less in univariate analysis, were included in a multivariate logistic regression model with a stepwise backward procedure.

Continuous variables were divided into terciles to allow their categorization.

Coefficients were calculated using the maximum likelihood method. All statistical calculations were performed using SPSS software (IBM Corporation, Armonk, NY, USA).

\section{Results}

Three hundred patients (184 men/116 women) with a mean age at diagnosis of $36 \pm 12$ (range, 14-73) were studied. All patients were Mauritanians. The demographic, clinical and serologic characteristics of the patients are shown in Table 1.

\section{Serological analyses}

Among the 296 confirmed $\mathrm{HBsAg}$ positive patients, only 21 were $\mathrm{HBeAg}$ positive and 270/291 tested had anti-HBeAb. Among the HBsAg positive patients, 98 (33.1\%) had total anti-HDVAb, and among these latter 56 (57.1\%) also had IgM anti-HDVAb (Table 1).

\section{Demographic and epidemiological data}

As shown in Table 1, anti-HDVAb positive patients were significantly older than the anti-HDV negative ones ( $41 \pm 12$ vs. $33 \pm 11$ years, $p<0.001)$.

We found no ethnical differences between co-infected and mono-infected patients. Interestingly, parenteral exposure was significantly more frequent in anti-HDVAb positive patients $(p=0.002)$.

\section{Clinical features}

As shown in Table 1, hepatomegaly, signs of liver insufficiency or portal hypertension were found more frequently in anti-HDVAb positive vs. anti-HDVAb negative patients. Abnormal liver ultrasound findings were also more frequently reported in HDVAb positive patients $(p=0.002)$.

\section{HBV and HDV molecular analyses}

HBV-DNA was quantified in the sera of all patients. When detectable with our technique, the mean HBV VL was $3.7 \pm 1.7 \mathrm{log} \mathrm{IU} / \mathrm{mL}$ (median $=3.04 \mathrm{IU} / \mathrm{mL}$, interquartile difference (IQD) $=1.95 \log \mathrm{IU} / \mathrm{mL}$ ). Only 53 out of the 296 (17.9\%) HBsAg positive patients had a viral load $>3.3 \mathrm{log}$ IU/ $\mathrm{mL}(>2000 \mathrm{IU} / \mathrm{mL})$, and 25 (8.4\%) had a viral load exceeding $5 \mathrm{log} \mathrm{IU} / \mathrm{mL}$. In the group of anti-HDVAb positive patients, $18.4 \%$ had a HBV viral load $>3.3$ vs. $81.6 \%<3.3 \mathrm{log} \mathrm{IU} / \mathrm{mL}$ (Table 1).

In this cohort, HBV-DNA level was not significantly different in HDVAb positive vs. negative patients (Table 1).

HDV-RNA was detectable in $62.2 \%$ of the 98 patients positive for HDVAb, in $82.1 \%$ of anti HDV IgM (Ab) positive patients and in $35.7 \%$ of anti HDV IgM (Ab) negative patients (Table 2). The mean HDV VL was $4.06 \pm 2.11$ log copies $/ \mathrm{mL}$.

HDV replication was associated with various levels of HBV replication. We observed a simultaneous high replication of the two viruses in 8 out of the 61 (13.1\%) patients (HBV DNA > $3.3 \log \mathrm{IU} / \mathrm{mL}$ and HDV RNA >4 log copies $/ \mathrm{mL}$ ) (Fig. 1).

HBV genotypes could be determined in 114 samples. $\mathrm{HBV} / \mathrm{D}$ was found in 69 patients $(60 \%)$, followed by $\mathrm{HBV} / \mathrm{E}$ (39, 34.2\%), HBV/A (5, 4.3\%) and HBV/G (1, 0.7\%). Several $\mathrm{HBV} / \mathrm{D}$ subgenotypes were identified, including HBV/D1 $(n=41), / \mathrm{D} 7(n=9)$, /D2 $(n=1), \mathrm{D} / 4(n=1)$ and the /D8 subgenotype $(n=17)$, recently described in Niger. ${ }^{21}$ Further molecular characterization of these strains is ongoing in the laboratory. The overall distribution of HBV genotypes according to patient anti-HDVAb status is shown in Table 1 and in Fig. 2. 
Table 1 Characteristics of the 298 patients included in this study according to the presence of anti HDV antibodies (HDVAb), AST: aspartate aminotransferase; ALT: alanine aminotransferase; $\gamma \mathrm{GT}$ : gamma-glutamyl transferase; IQD: interquartile difference, FM: FibroMeter.

\begin{tabular}{|c|c|c|c|c|}
\hline & \multicolumn{4}{|c|}{ HDVAb status } \\
\hline & All & HDVAb - & HDVAb + & $p^{a}$ \\
\hline N (\%) & 296 & $198(66.9)$ & $98(33.1)$ & - \\
\hline Age (years) $(M \pm S D)$ & $36 \pm 12$ & $33 \pm 11$ & $41 \pm 12$ & $<0.001$ \\
\hline Gender $(\% M)$ & 61.5 & 59.1 & 66.3 & 0.189 \\
\hline \multicolumn{5}{|l|}{ Ethnic group } \\
\hline White Moor & 205 & $133(67.2)$ & 72 (73.5) & 0.081 \\
\hline Black Moor & 58 & $37(18.7$ & $21(21.4)$ & \\
\hline Others African ethnic groups & 32 & $27(13.6)$ & $5(5.1)$ & \\
\hline \multicolumn{5}{|l|}{ Clinical features: $n$ (\%) } \\
\hline Jaundice & 13 & $6(3)$ & $7(7.2)$ & 0.43 \\
\hline Hepatomegaly & 22 & $6(3)$ & $16(16.33)$ & $<0.001$ \\
\hline Signs of liver insufficiency or portal hypertension & 31 & $12(6)$ & $19(19.33)$ & $<0.001$ \\
\hline Abnormal ultrasound examination of the liver & 23 & $7(3.6)$ & $16(16.33)$ & 0.003 \\
\hline Asymptomatic & 207 & $167(84.4)$ & $40(40.8)$ & $<0.001$ \\
\hline \multicolumn{5}{|l|}{ At least one parenteral exposure ${ }^{b}$} \\
\hline Yes & 104 & $58(29.3)$ & $46(46.9)$ & 0.003 \\
\hline No & 192 & $140(70.7)$ & $52(53.1)$ & \\
\hline \multicolumn{5}{|l|}{ Blood markers (Median, IQD) } \\
\hline AST (IU/L) & 296 & $25(23)$ & $50(48)$ & $<0.001$ \\
\hline ALT (IU/L) & 296 & $16(18)$ & $29.50(34)$ & $<0.001$ \\
\hline Platelets (g/L) & 295 & $243(119)$ & $183(160)$ & $<0.001$ \\
\hline Bilirubin $(\mu \mathrm{m} / \mathrm{L})$ & 295 & $13(11)$ & $17(12)$ & $<0.001$ \\
\hline Prothrombin time (\%) & 294 & $88(19)$ & $81(28)$ & $<0.001$ \\
\hline$\gamma \mathrm{GT}(\mathrm{IU} / \mathrm{L})$ & 294 & $25(26)$ & $34(52)$ & $<0.001$ \\
\hline Urea $(\mathrm{mmol} / \mathrm{L})$ & 296 & $3.15(1.67)$ & $3.32(1.83)$ & 0.039 \\
\hline Alpha-2 macroglobulin (g/L) & 293 & $265(96)$ & $284(114)$ & 0.009 \\
\hline Hyaluronic acid $(\mu \mathrm{g} / \mathrm{L})$ & 295 & $23.1(22.2)$ & $74.8(188.8)$ & $<0.001$ \\
\hline \multicolumn{5}{|l|}{ Score for determination of liver fibrosis (Median, IQD) } \\
\hline APRI Test & 295 & $0.18(0.24)$ & $0.52(0.78)$ & $<0.001$ \\
\hline FibroMeter & 289 & $0.35(0.38)$ & $0.77(0.51)$ & $<0.001$ \\
\hline Significant fibrosis (score APRI) ( $n, \%)$ & & & & $<0.001$ \\
\hline Yes & 22 & $7(4)$ & $15(23.4)$ & \\
\hline No & 219 & $170(96)$ & $49(76.6)$ & \\
\hline ND & 55 & 21 & 34 & \\
\hline Cirrhosis (score APRI) (n, \%) & & & & 0.002 \\
\hline Yes & 15 & $5(2.6)$ & $10(10.6)$ & \\
\hline No & 263 & $189(97.4)$ & $74(89.4)$ & \\
\hline ND & 8 & 4 & 4 & \\
\hline Severe liver fibrosis (SLF) $(F M>0.9)$ & & & & $<0.001$ \\
\hline Yes & 44 & $10(5)$ & $34(35.4)$ & \\
\hline No & 242 & $180(95)$ & $62(44.6)$ & \\
\hline $\operatorname{HBeAb}(+)(n)$ & 270 & 183 & 87 & NS \\
\hline HBV-DNA (log UI/ml) (Median, IQD) & 296 & $2.9(1.7)$ & $3.7(2.1)$ & 0.07 \\
\hline HBV-DNA > $3.3(\log U \mathrm{UImL})(n, \%)$ & & & & 0.87 \\
\hline Yes & 53 & $35(17.7)$ & $18(18.3)$ & \\
\hline No & 243 & $163(82.3)$ & $80(91.7)$ & \\
\hline HBV genotypes ( $n, \%)$ & 113 & 77 & 36 & NS \\
\hline $\mathrm{HBV} / \mathrm{A}$ & 5 & $3(3.9)$ & $2(5.6)$ & \\
\hline $\mathrm{HBV} / \mathrm{D}$ & 69 & $47(61)$ & $22(61.1)$ & \\
\hline $\mathrm{HBV} / \mathrm{E}$ & 39 & $27(35.1)$ & $12(33.3)$ & \\
\hline
\end{tabular}

a $t$ test or Wilcoxon test, according to the distribution.

b Injections, nosocomial infection, history of hospitalization, history of transfusion. 
Table 2 Blood markers, molecular analysis and scores for the determination of liver fibrosis for the 98 patients included in this study according to hepatitis delta virus as measured by the detection of HDV RNA, FM: FibroMeter.

\begin{tabular}{|c|c|c|c|c|}
\hline & \multicolumn{4}{|c|}{$\underline{\text { HDV RNA status (in HDVAb + patients) }}$} \\
\hline & All & HDV RNA - & HDV RNA + & $p$ \\
\hline$n$ & 98 & $37(37.7 \%)$ & $61(62.2 \%)$ & - \\
\hline Age (years) $(M \pm S D)$ & $36 \pm 12$ & $43.8( \pm 13.2)$ & $39.4( \pm 11.3)$ & 0.084 \\
\hline Gender (\%M) & 66.3 & 54.1 & 73.8 & 0.038 \\
\hline \multicolumn{5}{|l|}{ Clinical features $(n, \%)$} \\
\hline Jaundice & 7 & 5 & 2 & NA \\
\hline Hepatomegaly & 16 & 6 & 10 & 0.6 \\
\hline Signs of liver insufficiency or portal hypertension & 19 & 6 & 13 & 0.4 \\
\hline Abnormal Ultrasound examination of the liver & 16 & 5 & 11 & 0.7 \\
\hline HDVAb $(\operatorname{lgM})(n, \%)$ & & & & $<0.001$ \\
\hline Positive & 56 & $10(17.9 \%)$ & $46(82.1 \%)$ & \\
\hline Negative & 42 & 27 (64.3\%) & $15(35.7 \%)$ & \\
\hline \multicolumn{5}{|l|}{ Score for determination of liver fibrosis } \\
\hline Test-APRI & 98 & $1.19( \pm 2.47)$ & $0.73( \pm 0.72)$ & 0.27 \\
\hline FM & 96 & $0.62( \pm 0.34)$ & $0.74( \pm 0.23)$ & 0.06 \\
\hline Fibrosis (score APRI) & & 27 & 37 & 0.76 \\
\hline Yes & 15 & $7(31.8 \%)$ & $15(68.2 \%)$ & \\
\hline No & 49 & $20(40.8 \%)$ & $29(59.2 \%)$ & \\
\hline Cirrhosis (score APRI) & 84 & 31 & 53 & 0.16 \\
\hline Yes & 10 & $6(60 \%)$ & $4(40 \%)$ & \\
\hline No & 74 & $25(33.8 \%)$ & $49(66.2 \%)$ & \\
\hline$F M>0.9$ & 96 & $13(35.1 \%)$ & $24(40.7 \%)$ & 0.5 \\
\hline
\end{tabular}

HDV genotyping was successful in 47 sera. Among them, $40(85 \%)$ were HDV-1 and 7 (15\%) were HDV-5.

In 22 patients, both HBV and HDV genotypes of the infecting strains could be obtained. We could not find any particular HBV genotype/subtype distribution in the patients infected by different HDV genotypes: 20 (91\%) were HDV-1, of which 13 were associated with HBV/D and 7 with $\mathrm{HBV} / \mathrm{E}$; the 2 remaining strains were HDV-5 associated with HBV/E (Fig. 2).

\section{Liver fibrosis and cirrhosis}

Results of liver tests and blood markers of liver fibrosis according to patient anti-HDVAb or HDV-RNA positive or negative status are shown in Tables 1 and 2 respectively.
Patients with anti-HDVAb had higher ALT, AST and bilirubin levels, and lower platelet counts and prothrombin time. Similarly, $\alpha 2$ macroglobulin and hyaluronic acid concentrations were also higher in these patients (Table 1). They also had significantly higher scores of fibrosis with APRI and FM $(p<0.001)$.

According to FM, Metavir stages of fibrosis in the 298 patients were distributed as follows: F0/1: 25.5\%, F1: 16.2\%, F1/2: 23.1\%, F2/3: 14.8\%, F3/4: 11.4\%, F4: $9.0 \%$. Fig. 3 shows the repartition of Metavir stages in anti-HDVAb positive vs. anti-HDVAb negative groups.

Similarly, SLF, arbitrarily defined as FM $>0.9$, or SF (APRI $>1.5$ ) and cirrhosis (APRI $>2$ ), were significantly associated with the presence of anti-HDVAb with a $p$ value of $<0.001$, 0.001 and 0.003 respectively (Table 1$)$. However, when

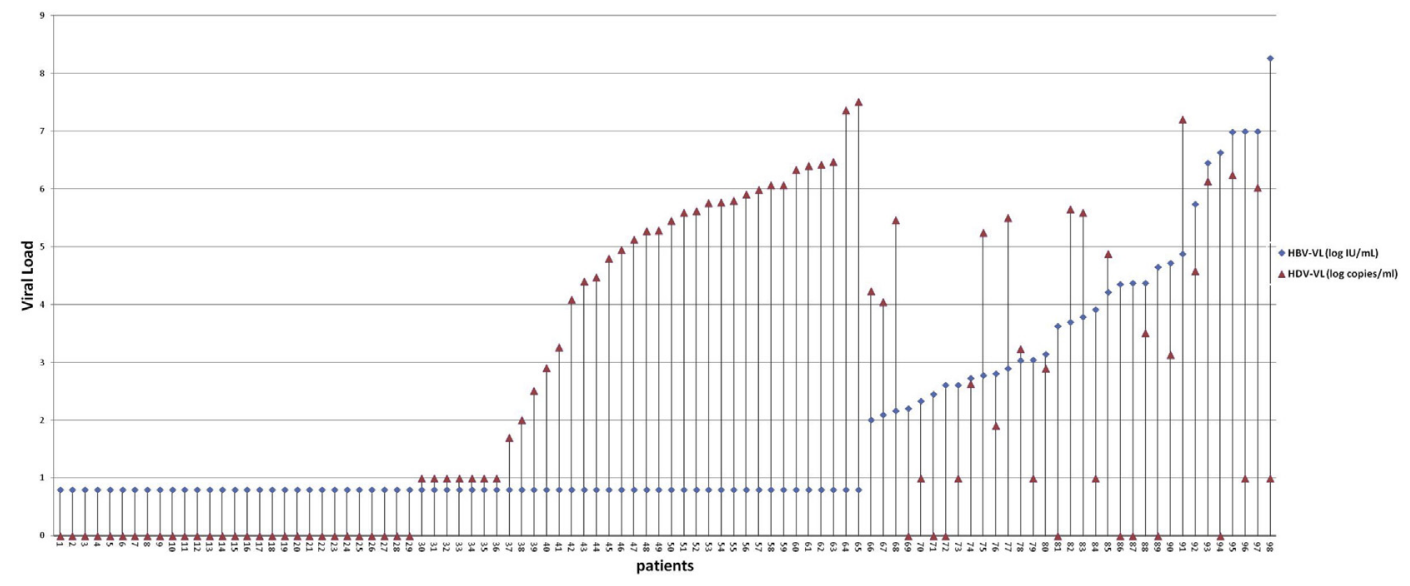

Figure 1 Dispersion of viral load (VL) values for HBV and HDV in HDV-Ab-positive patients. 
$\mathbb{H}$ HDV NEG

- HDV-1

口 HDV -5

$\square$ HDV-ND

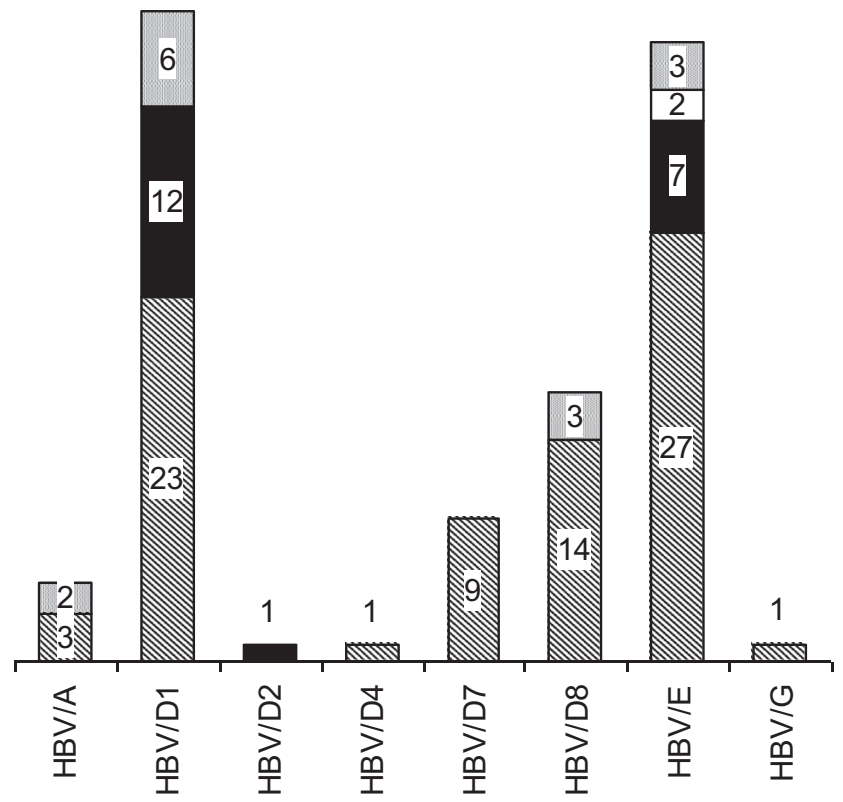

Figure 2 Distribution of HBV and HDV (sub) genotypes. HDV NEG: HDV negative; HDV-ND: HDV genotype not determined in HDVAb positive patients with negative or very low viral load. The number of strains is indicated.

comparing HDV-RNA positive vs. HDV-RNA negative patient groups, this difference was at the limit of statistical significance $(p=0.06)$, (Table 2$)$. We found no association between the severity of liver disease and anti $D$ IgM $A b$ or level of HDV RNA (data not shown).

Liver fibrosis was also evaluated by univariate and multivariate analyses. SLF, SF and cirrhosis were associated with (i) the presence of HDVAb, and (ii) a high HBV viral load $\geq 3.7 \mathrm{log} \mathrm{IU} / \mathrm{mL}$ (third tercile); in addition, SLF when assessed by FM was also associated with male gender (see Table 3a, 3b, 4a and 4b).

\section{Discussion}

This study confirms that Mauritania is highly endemic for HDV. Among 296 consecutive HBsAg positive patients attending the hepato-gastroenterology unit of the $\mathrm{CHN}$ for diagnosis or follow-up of hepatitis B infection, $33.1 \%$ had detectable anti-HDVAb. These patients were rather young (mean age 36 ), mainly men (66.3\%), and older ( $>8$ years) than the HBV mono-infected ones. These facts reinforce the hypothesis that HDV infection occurs after that of HBV, either sexually or more likely parenterally (i.e., nosocomially), as we described earlier in different populations of Mauritania. ${ }^{7,8}$

One main point of the present study is that it highlights the causative role of HDV infection in more severe liver disease as described elsewhere. ${ }^{9-11,22,23}$ Indeed, in patients who had anti-HDVAb, we found more often clinical or ultrasound signs of SF, higher ALT, AST and bilirubin levels, and direct/indirect markers of liver fibrosis, i.e., lower platelet counts, lower prothrombin times, and high levels of $\alpha 2$ macroglobulin and hyaluronic acid. APRI and FM scores for fibrosis or cirrhosis were also significantly increased in these patients, confirming our preliminary results. ${ }^{16}$

Contrary to what is usually found, HDV superinfected patients were significantly older than HBV-infected only. In fact, in Africa, it is generally admitted that HBV infection is usually acquired later than in Asia where HBV is more often transmitted from mother to child, most of the time during the childhood, or during the first sexual contacts. It is also admitted that HDV infection is acquired later than HBV and than in northern countries, where transmission occurs more frequently in intravenous or intranasal drug users. In previous studies performed in Mauritania, ${ }^{7,8}$ we have shown, in multivariate analyses, that, in 946 patients (mean age : $36.4 \pm 13.9$ years)screened for HBV and HDV, the presence of HDVAb was significantly correlated with age, mean age of HDVAb + patients being $41.5 \pm 13.8$ vs. $35.2 \pm 12.2$ years in $\mathrm{HDVAb}(-)$ patients. It was not the case in pregnant women

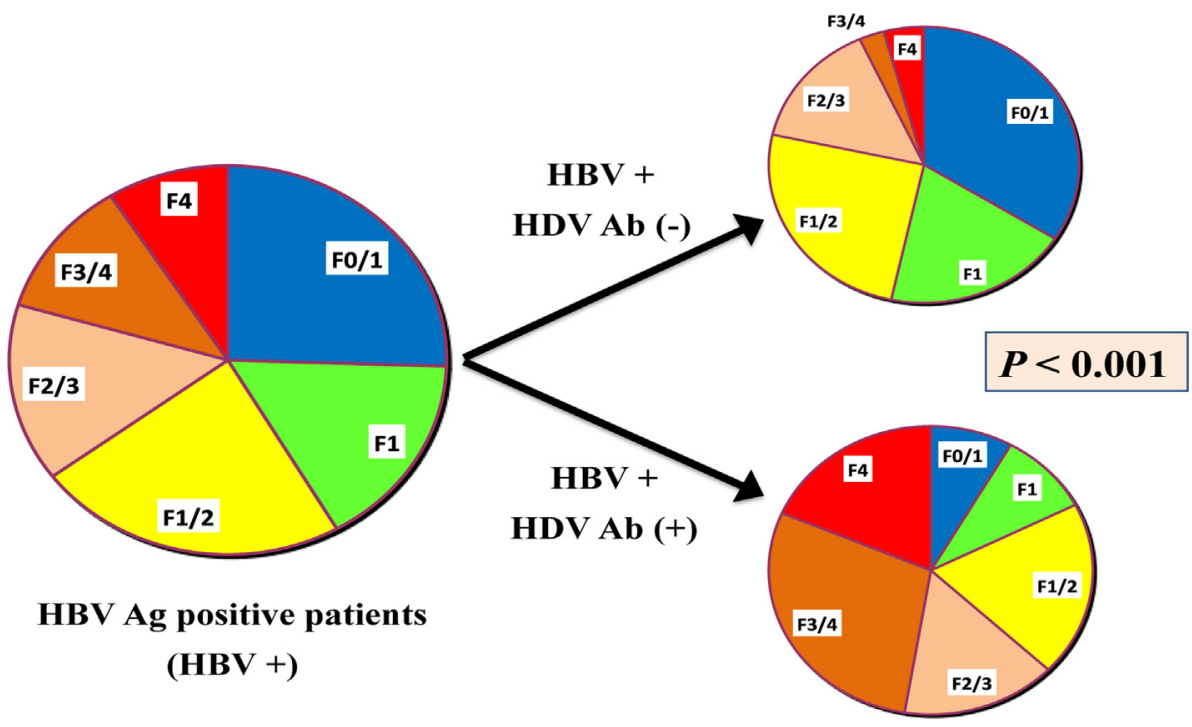

Figure 3 Classification F (Metavir) in HBsAg positive patients and comparison between HDVAb negative $(-)$ and HDVAb positive $(+)$ patients, using the FibroMeter. 
Table 3a Risk factors for significant fibrosis and for cirrhosis using the aspartate aminotransferase-to-platelet ratio index (APRI score): univariate analysis.

\begin{tabular}{|c|c|c|c|c|c|c|c|c|}
\hline & \multicolumn{4}{|c|}{ Significant fibrosis } & \multicolumn{4}{|l|}{ Cirrhosis } \\
\hline & \multirow{2}{*}{$\frac{\mathrm{APRI} \leq 0.50}{N(\%)}$} & \multirow{2}{*}{$\begin{array}{l}\text { APRI > } 1.50 \\
N(\%)\end{array}$} & \multirow{2}{*}{ OR $(95 \mathrm{Cl})^{\mathrm{a}}$} & \multirow[t]{2}{*}{$p$-Value } & \multirow{2}{*}{$\frac{\text { APRI } \leq 1.0}{N(\%)}$} & \multirow{2}{*}{$\begin{array}{l}\text { APRI > } 2.0 \\
N(\%)\end{array}$} & \multirow{2}{*}{ OR $(95 \mathrm{Cl})^{\mathrm{a}}$} & \multirow[t]{2}{*}{$p$-Value } \\
\hline & & & & & & & & \\
\hline \multicolumn{9}{|l|}{ Sex } \\
\hline Female & 124 (87.9\%) & 17 (12.1\%) & 1 (reference) & & $106(94 \%)$ & $5(6 \%)$ & 1 (reference) & \\
\hline Male & 95 (95\%) & $5(5 \%)$ & $0.38(0.14-1.1)$ & 0.065 & 263 (95.5\%) & $15(4.5 \%)$ & $0.7(0.2-2.2)$ & 0.6 \\
\hline \multicolumn{9}{|l|}{ Age (terciles) } \\
\hline$\leq 29$ years & 67 (90.5\%) & 7 (9.5\%) & 1 (reference) & & 80 (94.1\%) & $5(5.9 \%)$ & 1 (reference) & \\
\hline $30-39$ years & $80(92 \%)$ & $7(8 \%)$ & $1.2(0.35-4.0)$ & 0.75 & 93 (96.9\%) & $3(3.1 \%)$ & $0.52(0.09-2.6)$ & $0.48^{\mathrm{b}}$ \\
\hline$>39$ years & $67(89.3 \%)$ & $8(10.7 \%)$ & $0.88(0.27-2.8)$ & 0.81 & 85 (92.4\%) & 7 (7.6\%) & $1.32(0.4-5.0)$ & 0.65 \\
\hline \multicolumn{9}{|l|}{ Anti-HDVAb } \\
\hline Negative & 170 (96\%) & $7(4 \%)$ & 1 (reference) & & 74 (97.4\%) & $10(2.6 \%)$ & 1 (reference) & \\
\hline Positive & 49 (76.6\%) & $15(23.4 \%)$ & $7.4(2.9-19.3)$ & $<0.001$ & $263(88.1 \%)$ & $15(11.9 \%)$ & $5.1(1.7-15,4)$ & $0.03^{b}$ \\
\hline \multicolumn{9}{|l|}{ HDV RNA } \\
\hline Undetectable & $20(74.1 \%)$ & 7 (25.9\%) & 1 (reference) & & $49(80.6 \%)$ & $4(19.4 \%)$ & 1 (reference) & \\
\hline Detectable & $29(78.4 \%)$ & $8(21.6 \%)$ & $1.3(0.4-4.1)$ & 0.69 & 74 (92.5\%) & $10(7.5 \%)$ & $0.3(0.1-1.3)$ & $0.16^{\mathrm{b}}$ \\
\hline \multicolumn{9}{|l|}{ HBV DNA } \\
\hline Undetectable & 131 (91.6\%) & $12(8.4 \%)$ & 1 (reference) & & $153(95 \%)$ & $8(5 \%)$ & 1 (reference) & \\
\hline$<2.6 \log \mathrm{IU} / \mathrm{mL}$ & 31 (96.9\%) & $1(3.1 \%)$ & $0.35(0.02-2.8)$ & $0.47^{\mathrm{b}}$ & $39(100 \%)$ & 0 & $\begin{array}{l}\text { Undefined } \\
(0-2.8)\end{array}$ & $0.36^{\mathrm{b}}$ \\
\hline $2.6-3.7 \log \mathrm{IU} / \mathrm{mL}$ & $34(94.4 \%)$ & $2(6.6 \%)$ & $0.64(0.09-3.3)$ & $0.74^{\mathrm{b}}$ & 41 (95.3\%) & $2(4.7 \%)$ & $0.93(0.09-4.9)$ & $1.0^{\mathrm{b}}$ \\
\hline$>3.7 \log \mathrm{IU} / \mathrm{mL}$ & $23(76.7 \%)$ & 7 (23.3\%) & $3.3(1.05-10.4)$ & $0.03^{b}$ & 29 (85.3\%) & $5(14.7 \%)$ & $3.3(0.9-12.2)$ & $0.054^{\mathrm{b}}$ \\
\hline
\end{tabular}

and blood donors, but mean age was low $(26.5$ years in pregnant women and 31 years in blood donors). Age is also, indeed, generally associated with liver fibrosis and this parameter is included in the calculation of the FM. ${ }^{14}$ In the present study, age was not associated with LF or cirrhosis in univariate analysis and multivariate analysis was adjusted on age.

APRI and FM are currently used in chronic hepatitis $B,{ }^{13,24}$ but to our knowledge, they have been used in delta hepatitis infection only in a previous study by our team. ${ }^{24}$ Therefore, APRI and FM were useful tools to evaluate the severity of the hepatic disease in HBV- vs. HBV/HDVinfected patients of our cohort, particularly in the absence of liver biopsies which are not routinely performed in Mauritania.

More than one third of the cohort was anti-HDVAb positive, of whom $62 \%$ actively replicated the virus as assessed by the RNA viral load (mean $=4 \pm 2.11$ log copies $/ \mathrm{mL}$ ).

Table 3b Risk factors for significant fibrosis and for cirrhosis using the aspartate aminotransferase-to-platelet ratio index (APRI score): multivariate analysis.

\begin{tabular}{|c|c|c|c|c|}
\hline & \multicolumn{2}{|c|}{ Significant fibrosis $^{a}$} & \multicolumn{2}{|l|}{ Cirrhosis $^{\mathrm{b}}$} \\
\hline & AOR $(95 \mathrm{CI})^{c}$ & $p$-Value & AOR $(95 \mathrm{CI})^{c}$ & $p$-Value \\
\hline \multicolumn{5}{|l|}{ Sex } \\
\hline Female & 1 (reference) & & 1 (reference) & \\
\hline Male & $0.35(0.11-1.1)$ & 0.08 & $0.86(0.27-2.7)$ & 0.79 \\
\hline \multicolumn{5}{|l|}{ Anti-HDVAb } \\
\hline Negative & 1 (reference) & & & \\
\hline Positive & $8.3(2.9-23.8)$ & $<0.001$ & $4.6(1.5-14.4)$ & 0.008 \\
\hline \multicolumn{5}{|l|}{ HBV DNA } \\
\hline Undetectable & 1 (reference) & & 1 (reference) & \\
\hline$<2.6 \log \mathrm{IU} / \mathrm{mL}$ & $0.7(0.08-6.5)$ & 0.78 & Undefined & 0.99 \\
\hline $2.6-3.7 \mathrm{log} \mathrm{IU} / \mathrm{mL}$ & $1.2(0.2-6.0)$ & 0.86 & $1.1(0.2-5.6)$ & 0.89 \\
\hline$>3.7 \log \mathrm{IU} / \mathrm{mL}$ & $4.9(1.5-16.0)$ & 0.008 & $3.7(1.1-12.8)$ & 0.036 \\
\hline
\end{tabular}


Table 4a Risk factors for severe liver fibrosis according to the FibroMeter: univariate analysis.

\begin{tabular}{|c|c|c|c|c|}
\hline & \multicolumn{4}{|l|}{ FibroMeter } \\
\hline & $\leq 0.9$ & $>0.9$ & OR $(95 \mathrm{Cl})^{\mathrm{a}}$ & $p$-Value \\
\hline & $N(\%)$ & $N(\%)$ & & \\
\hline \multicolumn{5}{|l|}{ Sex } \\
\hline Female & 102 (92.7\%) & $8(7.3 \%)$ & 1 (reference) & \\
\hline Male & 140 (79.5\%) & $36(20.5 \%)$ & $3.3(1.5-7.3)$ & 0.003 \\
\hline \multicolumn{5}{|l|}{ Anti-HDVAb } \\
\hline Negative & $180(94.7 \%)$ & $10(5.3 \%)$ & 1 (reference) & \\
\hline Positive & $62(64.6 \%)$ & $34(35.4 \%)$ & $9.9(4.4-22.8)$ & $<0.001$ \\
\hline \multicolumn{5}{|l|}{ HDV RNA } \\
\hline Undetectable & $24(64.9 \%)$ & $13(35.1 \%)$ & 1 (reference) & \\
\hline Detectable & $38(64.4 \%)$ & $21(35.6 \%)$ & $1.02(0.4-2.6)$ & 0.96 \\
\hline \multicolumn{5}{|l|}{ HBV DNA (terciles) } \\
\hline Undetectable & $143(88.8 \%)$ & $18(11.2 \%)$ & 1 (reference) & \\
\hline$<2.6 \log \mathrm{IU} / \mathrm{mL}$ & $38(92.7 \%)$ & $3(7.3 \%)$ & $0.63(0.14-2.4)$ & 0.47 \\
\hline $2.6-3.7 \log \mathrm{IU} / \mathrm{mL}$ & 37 (90.2\%) & $4(9.8 \%)$ & $0.86(0.23-2.9)$ & 0.79 \\
\hline$>3.7 \log \mathrm{IU} / \mathrm{mL}$ & $23(54.8 \%)$ & $19(45.2 \%)$ & $6.6(2.8-15.4)$ & $<0.001$ \\
\hline
\end{tabular}

We found a very good correlation between the presence of IgM anti-HDVAb and HDV-RNA. However, IgM Ab are lacking in nearly $24.6 \%$ of the RNA positive patients, similarly to what we observe in our clinical practice (about $20 \%$ ) and as described elsewhere. ${ }^{25}$ Whether or not this is due to a lack of sensitivity of the tests or to virus strain replication remains to be elucidated. Some authors have suggested that IgM anti-HDVAb testing might provide additional useful information to determine disease activity in hepatitis delta and to predict responses to treatment with type 1 interferon. ${ }^{26}$ However, in our work, scores of fibrosis were not statistically different between $\lg M$ positive and negative patients.

Table 4b Risk factors for severe liver fibrosis: multivariate analysis.

\begin{tabular}{|c|c|c|}
\hline & \multicolumn{2}{|l|}{ Severe fibrosis ${ }^{a}$} \\
\hline & AOR $(\mathrm{Cl} 195)^{\mathrm{b}}$ & $p$-Value \\
\hline \multicolumn{3}{|l|}{ Sex } \\
\hline Female & 1 (reference) & \\
\hline Male & 3.7 (1.4-9.7) & 0.008 \\
\hline \multicolumn{3}{|l|}{ Anti-HDVAb } \\
\hline Negative & 1 (reference) & \\
\hline Positive & $16.1(6.2-41.6)$ & $<0.001$ \\
\hline \multicolumn{3}{|l|}{ HBV DNA (terciles) } \\
\hline Undetectable & 1 (reference) & \\
\hline$<2.6 \log \mathrm{IU} / \mathrm{mL}$ & $1.3(0.3-5.4)$ & 0.74 \\
\hline $2.6-3.7 \log \mathrm{IU} / \mathrm{mL}$ & $1.4(0.4-5.2)$ & 0.57 \\
\hline$>3.7 \log \mathrm{IU} / \mathrm{mL}$ & $13.6(4.8-38.6)$ & $<0.001$ \\
\hline
\end{tabular}

HDV RNA was not included in the model because of a strong colinearity with anti-HDV Ab; as age is used to calculate the FibroMeter score, it was not included in the model.

${ }^{a}$ FibroMeter $>0.9$.

b Adjusted odds ratio and $95 \%$ confidence interval.
HBV-DNA viral load is usually low during HDV infection due to inhibition of HBV replication. ${ }^{27,28}$ In this study, although the majority (81.6\%) of HDV-infected patients generally had low levels of HBV DNA $(<3.3 \log \mathrm{IU} / \mathrm{mL})$, the mean HBV DNA level was not significantly lower in HDV co-infected vs. HBV mono-infected patients as generally reported. ${ }^{22} \mathrm{HDV}$ infection does not seem to suppress HBV replication in our cohort. The fact that a significant proportion (144/198, 71.7\%) of HBV mono-infected patients were inactive carriers of HBV (normal ALT and HBV DNA $<3.3 \log \mathrm{IU} / \mathrm{mL}$ ), may be an explanation. Interestingly also, we did find simultaneous replication of both viruses in $13.1 \%$ of the co-infected patients, with high levels of HBV DNA (Fig. 1), as this has also been described elsewhere ${ }^{29}$ showing again that HDV does not always suppress HBV.

Moreover, we found that high HBV load ( $>3.7 \log \mathrm{IU} / \mathrm{mL}$ ) and anti-HDVAb were independently associated with both SLF and cirrhosis.

High HBV DNA levels was shown to be significantly and independently associated with incidences of cirrhosis and hepatocellular carcinoma (HCC). ${ }^{30,31}$ Thus, according to our data, high HBV VL is also a marker of severe outcome in HDV-infected patients.

Conversely, HDV-RNA levels were not associated with the severity of fibrosis as usually stated. ${ }^{22}$ It is noteworthy that $37.7 \%$ of the HDV-infected patients had undetectable HDV RNA, indicating that they had either cleared the virus or had very low levels of RNA. This suggests that a history of HDV infection itself, as assessed by the specific antibody response, rather than the replication level of the virus, is responsible for the pejorative evolution of hepatic disease. Indeed, recent studies performed by us and others showed that the large HDV antigen (LHDAg) is able to transactivate several genes involved in cell proliferation or in fibrosis. ${ }^{32,33}$ Therefore, the high prevalence of HCC in sub-Saharan Africa $^{34,35}$ may in part, be explained by the high rate of HDV 
infections, as assessed by the significant association between HDVAbs and SF or SLF. We are currently performing a clinical study in patients of the CHN hepatogastroenterology unit who have been hospitalized with cirrhosis or HCC, in order to determine the possible role for HDV in liver related morbidity in Mauritania.

Genetic variability of the strains has also been incriminated in the severity of disease. HBV/D, /E and / A, and HDV -1 and -5 have been described in Mauritania. We found no difference in the distribution of HBV genotypes among anti-HDVAb positive and anti-HDVAb negative patients in our cohort (Fig. 2). There was also no significant difference in severity of disease according to HBV genotypes (results not shown). Very little is known for HDV genotypes. The African genotypes HDV -5 to -8 have been recently characterized $^{19,36}$ and studies are lacking on the severity of these genotypes. In the present study, patients were infected mainly with HDV-1 (85\%) and with HDV-5 (15\%). We did not find any difference in the severity of liver disease according to HDV genotype.

Therefore, further studies are needed to determine a possible role of $\mathrm{HBV}$ and/or HDV genotypes/subtypes, in the natural history of liver disease particularly the D8 subgenotype.

In summary, we provide here the first study of the impact of HDV co- or super-infection in a study population of over 300 consecutive patients in Mauritania, a Saharan country characterized by a very high prevalence of HBV (up to 20\%) and HDV (up to 33\%). HDV is responsible for a more severe disease in both clinical and biological terms. Also, its causative role in liver morbidity in Africa may be underestimated. We also show that non-invasive tests, such as FibroMeter, may be useful for the assessment of liver fibrosis, and together with classical biology and ultrasonographic tools, may help to optimize management of infected patients in African countries.

\section{Financial support}

This work was supported and financed by the French National Agency for Research on AIDS and viral hepatitis (ANRS) (Project ANRS-12166).

\section{Potential conflict of interest}

All authors: No reported conflicts.

\section{Acknowledgments}

We thank Professor Paul Calès for making FibroMeter available to us and for his assistance in calculating fibrosis scores. We also thank Yves Gallois for performing specialized biological analyses.

We thank Abbott, Diasorin and BioMerieux for their assistance.

We also express our thanks to all those who helped us carry out our study: Dr Meymouna Mint Moctar, Mr. Mohamed El Moctar Ould Mohamed Vall, Mr. Mohamed Ould Salem and Mr. Amadou Sao.
We also thank the embassy of France in Nouakchott and particularly Mr. Michel Treutenaere and Professor Alain Carayon.

\section{References}

1. Gaeta GB, Stroffolini T, Chiaramonte M, Ascione T, Stornaiuolo G, Lobello S, et al. Chronic hepatitis D: a vanishing disease? An Italian multicenter study. Hepatology 2000;32(4 Pt 1):824-7.

2. Rizzetto M. Hepatitis D: thirty years after. J Hepatol 2009; 50(5):1043-50.

3. Makuwa M, Mintsa-Ndong A, Souquiere S, Nkoghe D, Leroy EM, Kazanji M. Prevalence and molecular diversity of hepatitis B virus and hepatitis delta virus in urban and rural populations in northern Gabon in central Africa. J Clin Microbiol 2009; 47(7):2265-8.

4. Makuwa M, Caron M, Souquiere S, Malonga-Mouelet G, Mahe A, Kazanji M. Prevalence and genetic diversity of hepatitis $B$ and delta viruses in pregnant women in Gabon: molecular evidence that hepatitis delta virus clade 8 originates from and is endemic in central Africa. J Clin Microbiol 2008;46(2):754-6.

5. Wedemeyer H, Heidrich B, Manns MP. Hepatitis D virus infection - not a vanishing disease in Europe! Hepatology 2007; 45(5):1331-2 [author reply 1332-3].

6. Foupouapouognigni Y, Noah DN, Sartre MT, Njouom R. High prevalence and predominance of hepatitis delta virus genotype 1 infection in Cameroon. J Clin Microbiol 2011;49(3):1162-4.

7. Mansour W, Bollahi MA, Hamed CT, Brichler S, Le Gal F, Ducancelle A, et al. Virological and epidemiological features of hepatitis delta infection among blood donors in Nouakchott, Mauritania. J Clin Virol 2012;55(1):12-6.

8. Mansour W, Malick FZ, Sidiya A, Ishagh E, Chekaraou MA, Veillon $\mathrm{P}$, et al. Prevalence, risk factors, and molecular epidemiology of hepatitis $B$ and hepatitis delta virus in pregnant women and in patients in Mauritania. J Med Virol 2012;84(8):1186-98.

9. Romeo R, Del Ninno E, Rumi M, Russo A, Sangiovanni A, de Franchis R, et al. A 28-year study of the course of hepatitis delta infection: a risk factor for cirrhosis and hepatocellular carcinoma. Gastroenterology 2009;136(5):1629-38.

10. Buti M, Homs M, Rodriguez-Frias F, Funalleras G, Jardi R, Sauleda $S$, et al. Clinical outcome of acute and chronic hepatitis delta over time: a long-term follow-up study. J Viral Hepat 2011;18(6):434-42.

11. Mumtaz K, Ahmed US, Memon S, Khawaja A, Usmani MT, Moatter T, et al. Virological and clinical characteristics of hepatitis delta virus in South Asia. Virol J 2011;8:312.

12. Wai CT, Greenson JK, Fontana RJ, Kalbfleisch JD, Marrero JA, Conjeevaram HS, et al. A simple noninvasive index can predict both significant fibrosis and cirrhosis in patients with chronic hepatitis C. Hepatology 2003;38(2):518-26.

13. Bonnard P, Sombie R, Lescure FX, Bougouma A, GuiardSchmid JB, Poynard T, et al. Comparison of elastography, serum marker scores, and histology for the assessment of liver fibrosis in hepatitis B virus (HBV)-infected patients in Burkina Faso. Am J Trop Med Hyg 2010;82(3):454-8.

14. Cales P, Oberti F, Michalak S, Hubert-Fouchard I, Rousselet MC, Konate $A$, et al. A novel panel of blood markers to assess the degree of liver fibrosis. Hepatology 2005;42(6):1373-81.

15. Mbaye PS, Sarr A, Sire JM, Evra ML, Ba A, Daveiga J, et al. Liver stiffness measurement and biochemical markers in Senegalese chronic hepatitis B patients with normal ALT and high viral load. PLoS One 2011;6(7):e22291.

16. Si Ahmed S, Mansour W, Causse X, Le Gal F, Gordien E, Fouchard-Hubert I, et al. Impact of $B+$ Delta viruses co infection on the liver stiffness measurement (LSM) by transient elastography. J Hepatol 2008;48(S2):249. 
17. Cales P, Boursier J, Oberti F, Hubert I, Gallois Y, Rousselet MC, et al. FibroMeters: a family of blood tests for liver fibrosis. Gastroenterol Clin Biol 2008;32(6 Suppl. 1):40-51.

18. Le Gal F, Gordien E, Affolabi D, Hanslik T, Alloui C, Deny P, et al. Quantification of hepatitis delta virus RNA in serum by consensus real-time PCR indicates different patterns of virological response to interferon therapy in chronically infected patients. J Clin Microbiol 2005;43(5):2363-9.

19. Radjef N, Gordien E, Ivaniushina V, Gault E, Anais P, Drugan T, et al. Molecular phylogenetic analyses indicate a wide and ancient radiation of African hepatitis delta virus, suggesting a deltavirus genus of at least seven major clades. $J$ Virol 2004;78(5):2537-44.

20. Lindh M, Gonzalez JE, Norkrans G, Horal P. Genotyping of hepatitis $B$ virus by restriction pattern analysis of a pre-S amplicon. J Virol Methods 1998;72(2):163-74.

21. Abdou Chekaraou M, Brichler S, Mansour W, Le Gal F, Garba A, Deny $P$, et al. A novel hepatitis $B$ virus (HBV) subgenotype $D$ (D8) strain, resulting from recombination between genotypes $D$ and $E$, is circulating in Niger along with $\mathrm{HBV} / \mathrm{E}$ strains. $J$ Gen Virol 2010;91(Pt 6):1609-20.

22. Wedemeyer H, Manns MP. Epidemiology, pathogenesis and management of hepatitis D: update and challenges ahead. Nat Rev Gastroenterol Hepatol 2010;7(1):31-40.

23. Yurdaydin C, Idilman R, Bozkaya H, Bozdayi AM. Natural history and treatment of chronic delta hepatitis. J Viral Hepat 2010; 17(11):749-56.

24. Cales P, Boursier J, Bertrais S, Oberti F, Gallois Y, FouchardHubert I, et al. Optimization and robustness of blood tests for liver fibrosis and cirrhosis. Clin Biochem 2010;43(16-17): 1315-22.

25. Ozekinci T, Atmaca S, Akpolat N, Temiz H, Arikan E. Short communication: evaluation of the correlation between hepatitis D virus (HDV) RNA positivity and HDV antibodies. Mikrobiyol Bul 2005;39(3):345-9.

26. Mederacke I, Yurdaydin C, Dalekos GN, Bremer B, Erhardt A, Cakaloglu $Y$, et al. Anti-HDV immunoglobulin $M$ testing in hepatitis delta revisited: correlations with disease activity and response to pegylated interferon-alpha2a treatment. Antivir Ther 2012;17(2):305-12.

27. Sakugawa H, Nakasone H, Nakayoshi T, Kawakami $Y$, Yamashiro T, Maeshiro T, et al. Hepatitis B virus concentrations in serum determined by sensitive quantitative assays in patients with established chronic hepatitis delta virus infection. J Med Virol 2001;65(3):478-84.

28. Williams V, Brichler S, Radjef N, Lebon P, Goffard A, Hober D, et al. Hepatitis delta virus proteins repress hepatitis $B$ virus enhancers and activate the alpha/beta interferon-inducible MxA gene. J Gen Virol 2009;90(Pt 11):2759-67.

29. Le Gal F, Badur S, Hawajri NA, Akyuz F, Kaymakoglu S, Brichler S, et al. Current hepatitis delta virus type 1 (HDV1) infections in central and eastern Turkey indicate a wide genetic diversity that is probably linked to different HDV1 origins. Arch Virol 2012;157(4):647-59.

30. Iloeje UH, Yang HI, Su J, Jen CL, You SL, Chen CJ. Predicting cirrhosis risk based on the level of circulating hepatitis $B$ viral load. Gastroenterology 2006;130(3):678-86.

31. Chen CJ, Yang HI. Natural history of chronic hepatitis B REVEALed. J Gastroenterol Hepatol 2011;26(4):628-38.

32. Choi SH, Jeong SH, Hwang SB. Large hepatitis delta antigen modulates transforming growth factor-beta signaling cascades: implication of hepatitis delta virus-induced liver fibrosis. Gastroenterology 2007;132(1):343-57.

33. Williams V, Brichler S, Khan E, Chami M, Dény P, Kremsdorf D, et al. Large hepatitis delta antigen activates STAT-3 and NF-kB via oxidative stress. J Viral Hepat 2012:744-53.

34. Kew MC. Hepatocellular carcinoma in African Blacks: recent progress in etiology and pathogenesis. World J Hepatol 2010; 2(2):65-73.

35. Cainelli F. Liver diseases in developing countries. World J Hepatol 2012;4(3):66-7.

36. Le Gal F, Gault E, Ripault MP, Serpaggi J, Trinchet JC, Gordien E, et al. Eighth major clade for hepatitis delta virus. Emerg Infect Dis 2006;12(9):1447-50. 